\title{
1 Rhodanese Rdl2 produces reactive sulfur species to scavenge hydroxyl radical and
}

\section{2 protect mitochondria}

3 Qingda Wang ${ }^{1 \dagger}$, Zhigang Chen $^{1 \dagger}$, Xi Zhang ${ }^{1}$, Yuping Xin ${ }^{1}$, Yongzhen Xia ${ }^{1}$, Luying Xun ${ }^{1,2 *}$,

$4 \quad$ Huaiwei $\operatorname{Liu}^{1 *}$

$5 \quad{ }^{1}$ State Key Laboratory of Microbial Technology, Shandong University, Qingdao, 266237, PR

6 China;

$7 \quad{ }^{2}$ Department of Chemistry, School of Molecular Biosciences, Washington State University,

8 Pullman, WA, 99164-4630, USA.

$9 \quad$ These authors contribute equally to this work.

10

11

12 


\section{Abstract}

27 During aerobic respiration, mitochondria generate superoxide anion $\left(\mathrm{O}_{2}{ }^{--}\right)$, hydrogen peroxide $\left(\mathrm{H}_{2} \mathrm{O}_{2}\right)$, and hydroxyl radical $\left(\mathrm{HO}^{\circ}\right)$, and these reactive oxygen species (ROS) are detrimental to mitochondria. Mitochondrial damage is linked to a broad spectrum of pathologies such as Alzheimer's disease, hemochromatosis, and diabetes. Mitochondria contain several enzymes for rapidly removing superoxide anion and hydrogen peroxide, but how they antagonize $\mathrm{HO}^{\circ}$ is elusive, representing a loophole in the anti-ROS system. Herein, we discovered that Rhodanese $2(\operatorname{Rd} 12)$ is critical for maintaining the functionality and integrity of mitochondria under sub-lethal ROS stress in Saccharomyces cerevisiae. Rd12 converts stable sulfur species (thiosulfate and dialkyl polysulfide) to reactive sulfane sulfur including persulfide that protects mitochondrial DNA via scavenging $\mathrm{HO}^{\circ}$. Surprisingly, hydrogen sulfide $\left(\mathrm{H}_{2} \mathrm{~S}\right)$ promotes $\mathrm{HO}^{\bullet}$ production through stimulating the Fenton reaction, leading to increased DNA damage. Our study may reveal an ex-ante mean for antagonizing $\mathrm{HO}^{\bullet}$, patching the loophole of the anti-ROS system in mitochondria. mitochondria health 
49

50

51

52

\section{Introduction}

Mitochondria are essential organelles in eukaryotic cells. They produce about $80 \%$ of cellular energy via oxidative phosphorylation under oxic condition [1]. Further, they have other key functions including heme production, iron-sulfur cluster biogenesis, and calcium homeostasis [2]. Maintaining the functionality and integrity of mitochondria is critical for human health, and failing to do so would lead to a broad spectrum of pathologies, such as Alzheimer's, Parkinson's disease, hemochromatosis, atherosclerosis, carcinogenesis, and diabetes mellitus [3-6].

As a hectic distribution station of metabolites, mitochondria incessantly experience many types of stresses. A widely documented one is mediated by reactive oxygen species (ROS) that includes the superoxide anion $\left(\mathrm{O}_{2}^{-}{ }^{-}\right)$, the hydrogen peroxide $\left(\mathrm{H}_{2} \mathrm{O}_{2}\right)$ and the hydroxyl radical $\left(\mathrm{HO}^{\circ}\right)$ [7]. $\mathrm{O}_{2}{ }^{-}$is directly produced by Complex I, III, and IV via transferring one electron to $\mathrm{O}_{2}$. The scavenging of $\mathrm{O}_{2}{ }^{-}$is conducted by superoxide dismutases (SOD), which convert $\mathrm{O}_{2}{ }^{--}$to $\mathrm{H}_{2} \mathrm{O}_{2}$. GPX enzymes including peroxiredoxins, thioredoxins, and glutathione peroxidases are the major $\mathrm{H}_{2} \mathrm{O}_{2}$ scavengers [7,8]. SOD and GPX compose a major anti ROS system in mitochondria. Albeit the existence of these enzymes, a fraction of $\mathrm{H}_{2} \mathrm{O}_{2}$ still converts to $\mathrm{HO}^{\bullet}$ via the Fenton reaction. Different from $\mathrm{H}_{2} \mathrm{O}_{2}, \mathrm{HO}^{\bullet}$ is a very strong and labile oxidant (2.33 V, at $\mathrm{pH} 7)$ that rapidly reacts with most organic molecules, such as DNA, proteins, lipids, and polysaccharides, causing structural damages to mitochondria if out of control. It is commonly believed that mitochondria only have ex-post means for antagonizing $\mathrm{HO}^{*}-$ resorting to the repair systems for mending the damages [9], and no a specific enzyme 

maintain $\mathrm{HO}^{\circ}$ under lethal level is a loophole in their anti ROS system.

Although several RSS generation enzymes including cystathionine gamma-lyase, biogenesis leads to mitochondrial dysfunction, intimating a close connection between RSS biogenesis and mitochondrial health, but the underlying mechanism remains elusive [19,20]. 
92

93

94

95

96

97

98

health under ROS stress. Knocking out Rd12 results in the change of mitochondrial morphology, loss of mitochondrial DNA (mitDNA), reduction of oxidative phosphorylation efficiency, and change of iron metabolism. RSS generated by Rdl2 actively scavenges HO. Thus, an active mechanism to remove $\mathrm{HO}^{\bullet}$ might be identified.

\section{Materials and Methods}

\section{Strains and materials}

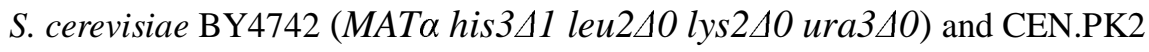

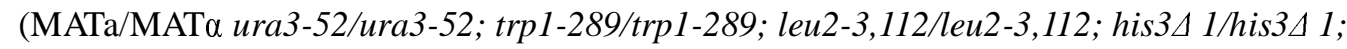

MAL2-8C/MAL2-8C; SUC2/SUC2) strains were cultured in yeast extract-peptone-dextrose

(YPD) medium or synthetic defined (SD) medium at $30^{\circ} \mathrm{C}$. The constructed mutants are listed in supplementary material (Table S1). E. coli DH5 $\alpha$ and BL21(DE3) strains were cultured in lysogeny broth (LB) medium at $37^{\circ} \mathrm{C}$. Thiosulfate and sodium hydrosulfide (NaHS) were purchased from Sigma-Aldrich (Saint Louis, MO). Dimethyl trisulfide (MeSSSMe) and $\mathrm{S}_{8}$ were purchased from TCI (Shanghai, China) Company. $\mathrm{HS}_{\mathrm{n}} \mathrm{H}$ and GSSH were prepared following the protocol of Luebke et al [23]. Other chemicals were purchased from local companies if not specifically mentioned.

Key methods were described as below and others were provided in supplementary material (Materials and methods).

\section{Subcellular Localization of Rdl1 and Rdl2.}

A GFP encoding sequence was fused to RDL1 and RDL2 C-termini in BY4742 
114 chromosome by using the one-step PCR-mediated gene disruption method [24]. Yeast cells

115 were collected by centrifugation $(10,000 \mathrm{~g}, 5 \mathrm{~min})$ and diluted to $1 \mathrm{OD}_{600}$ in sterile SD

116 medium containing $10 \mathrm{nM}$ Mito Tracker Red CMSRos (Thermo Fisher, Waltham, MA). The

117 cell suspensions were incubated at $30^{\circ} \mathrm{C}$ for $20 \mathrm{~min}$ in dark place and then washed three times

118 to remove the extracellular CMSRos. Yeast cells were suspended in water and imaged by

119 using a fluorescence microscope (Olympus IX83). GFP and CMSRos co-localization was

120 analyzed.

121 To analyze the expression level of fused Rdl2-GFP in different growth phages, Microplate

122 Reader Synergy H1 was used with $\lambda_{e x}$ of $488 \mathrm{~nm}$ and $\lambda_{e m}$ of $525 \mathrm{~nm}$. To analyze the expression

123 level of fused Rd12-GFP in the presence of $\mathrm{H}_{2} \mathrm{O}_{2}, 1 \mathrm{OD}_{600}$ middle-log phase yeast cells $(8 \mathrm{~h}$

124 cultivation) were treated with $5 \mathrm{mM} \mathrm{H}_{2} \mathrm{O}_{2}$ at $30^{\circ} \mathrm{C}$ for $1 \mathrm{~h}$, and then subjected to flow

125 cytometry analysis. For each sample, $10^{5}$ cells were analyzed in the FL1 channel and the

126 average fluorescence value was recorded.

Transcriptomic analysis 
136

137 polymerase I. Double-stranded cDNA was purified with AMPure XP and then A-tailing and sequencing adapters were connected. The AMPure XP beads were used for fragment size selection and PCR enrichment was perform to obtain the final cDNA library. The library was sequenced on Illumina NovaSeq 6000 platform. Sequencing was performed at Shanghai Applied Protein Technology Co., Ltd. The clean data were obtained from raw data by removing reads containing adapter, poly- $\mathrm{N}$ and low quality reads. The clean reads were aligned with the genome of S. cerevisiae BY4742 by using HISAT2. The featureCounts software was used to calculate the FPKM value of each gene expression in each sample. Genes with a p-vale $<0.05$ and fold change $>2$ were considered as significantly differentially expressed.

\section{Targeted metabolomics analysis}

For targeted metabolomics analysis, cells were harvested and quickly frozen in liquid nitrogen. After grinding with liquid nitrogen, $60 \mathrm{mg}$ cells were mixed with $1 \mathrm{ml}$ methanol acetonitrile aqueous solution $(2: 2: 1, \mathrm{v} / \mathrm{v})$ and vortexed for $60 \mathrm{~s}$. Cells were then disrupted using the ultra-sound method. The broken cells were placed at $-20{ }^{\circ} \mathrm{C}$ for $1 \mathrm{~h}$ and then centrifuged at $14,000 \mathrm{~g}$ for $20 \mathrm{~min}$ at $4^{\circ} \mathrm{C}$. The obtained supernatant was subjected to freeze-dry and then LC-MS analysis. The Waters I-class ultra performance liquid chromatography was used and the mobile phase A was an aqueous solution with $25 \mathrm{mM}$ ammonium acetate and $25 \mathrm{mM}$ ammonia $(\mathrm{pH}, 9.75)$. Mobile phase $\mathrm{B}$ was acetonitrile. Protein sample was placed in a $4^{\circ} \mathrm{C}$ autosampler, and the column temperature was set to $40^{\circ} \mathrm{C}$. The flow rate was $0.3 \mathrm{~mL} / \mathrm{min}$, and the injection volume was $2 \mu \mathrm{L}$. The liquid phase gradient was 
158

159

160

161

162

set as: 0-1 min, phase B at 95\%; 1-14 min, B linearly changing from $95 \%$ to $65 \%$; $14-16$ min, B linearly changing from $65 \%$ to $40 \% ; 16-18 \mathrm{~min}, \mathrm{~B}$ at $40 \% ; 18-18.1 \mathrm{~min}$, B linearly changing from $40 \%$ to $95 \%$; $18.1-23$ min, B at $95 \%$. In the sample cohort, one QC sample was set every six experimental repeats to detect and evaluate the stability and repeatability of the system.

The AB 5500 QqQ mass spectrometer (AB SCIEX, Framingham, MA) was sued for mass spectrometry analysis. The ESI source conditions were as: sheath gas temperature, $350^{\circ} \mathrm{C}$; dry gas temperature, $350^{\circ} \mathrm{C}$; sheath gas flow, $11 \mathrm{~L} / \mathrm{min}$; dry gas flow, $10 \mathrm{~L} / \mathrm{min}$; capillary voltage was $4000 \mathrm{~V}$ for positive mode and $-3500 \mathrm{~V}$ for negative mode; nozzle voltage, $500 \mathrm{~V}$; and nebulizer pressure, 30 psi. Monitor was in MRM mode and the dwell time of each MRM transition was $3 \mathrm{~ms}$, and the total cycle time wa $1.263 \mathrm{~s}$. MRMAnalyzer (R) was used to extract the original MRM data of 200 metabolites to obtain the peak area of each metabolite. Metabolites with $\mathrm{p}$-value $<0.05$ and fold change $>1.5$ were considered as at significantly different levels.

\section{Mitochondria preparation and mitochondrial RSS analysis}

S. cerevisiae mitochondria were isolated using differential centrifugation as described previously [25]. The fluorescence-based probe psGFP1.1 was expressed and localized into mitochondrial matrix of BY4742 as reported previously [26]. Mitochondria containing psGFP1.1 (mit-psGFP) were isolated and treated with sulfur containing chemicals in isolation buffer (1 mM EDTA, 0.6 M sorbitol, $10 \mathrm{mM}$ Tris-HCl, pH 7.4). The mixtures contained mitochondria and $400 \mu \mathrm{M}$ cysteine, thiosulfate, or MeSSSMe. After incubated at $30^{\circ} \mathrm{C}$ for $1 \mathrm{~h}$, 
180

181

182

183

184

treated mitochondria were centrifuged at $12,000 \mathrm{~g}$ for $15 \mathrm{~min}$ and washed with isolation buffer (1 mM EDTA, 0.6 M sorbitol, 10 mM Tris-HCl, pH 7.4). Fluorescence was detected using the Synergy H1 microplate reader. The emission intensities at $515 \mathrm{~nm}$ excited by both $408 \mathrm{~nm}$ and $488 \mathrm{~nm}$ were recorded, and the ratio of 408/488 was used to represent the reactive sulfane sulfur level in mitochondria. Explanation of the calculation principle can be found in a previous report [26].

\section{Radical-induced pDNA cleavage assay}

The pDNA cleavage assay was performed following the previously reported method [27].

The pBluescript II SK (+) plasmid was used as the model DNA. $25 \mu \mathrm{g} / \mu \mathrm{L}$ plasmid was mixed with $50 \mu \mathrm{M} \mathrm{Fe}^{2+}$ and $50 \mu \mathrm{M} \mathrm{H}_{2} \mathrm{O}_{2}$ in distilled water. The mixture was incubated at room temperature for $3 \mathrm{~h}$ and then analyzed by electrophoresis. The supercoiled (SC) and nicked circular (NC) forms of plasmid was quantified using the software FluorChem Q (Protein Simple, Inc.). SC ratio was calculated as $\mathrm{SC}(\mathrm{SC}+\mathrm{NC})$ and used as the DNA damage index. For testing the protection effect of $\operatorname{Rdl} 2$ products, $\operatorname{Rd} 12(2.5 \mu \mathrm{M})$ was incubated with $1 \mathrm{mM}$ thiosulfate or MeSSSMe at room temperature for $1 \mathrm{~h}$, and then Rdl2 was removed using a 3-kDa filter. The filtrated products were diluted with HEPES buffer (100 mM, pH 7.4) to prepare product-dilution solutions, which were added into the DNA-Fe ${ }^{2+}-\mathrm{H}_{2} \mathrm{O}_{2}$ mixture and subjected to the same analysis. Thiosulfate, MeSSSMe, $\mathrm{H}_{2} \mathrm{~S}$ (in the form of NaHS), $\mathrm{S}_{8}$, laboratory prepared GSSH, GSH, and L-ascorbic acid were also tested in the same conditions. For testing whether $\mathrm{H}_{2} \mathrm{~S}$ reduces $\mathrm{Fe}^{3+}$ to promote the Fenton reaction, $25 \mu \mathrm{g} / \mu \mathrm{L}$ plasmid was incubated with $50 \mu \mathrm{M} \mathrm{Fe}{ }^{3+}, 50 \mu \mathrm{M} \mathrm{H}_{2} \mathrm{O}_{2}$ and NaHS or $\mathrm{S}_{8}(20 \mu \mathrm{M}-300 \mu \mathrm{M})$ at room 
202

203

204

205

206

207

208

209

210

211

212

213

214

215

216

217

218

219

220

221

222

223 temperature for $3 \mathrm{~h}$. As the control, $25 \mu \mathrm{g} / \mu \mathrm{L}$ plasmid was incubated with $50 \mu \mathrm{M} \mathrm{H}_{2} \mathrm{O}_{2}$ and

NaHS $(20 \mu \mathrm{M}-300 \mu \mathrm{M})$ at room temperature for $3 \mathrm{~h}$. The untreated-plasmid DNA and the

Fenton solution-plasmid DNA mixture were also used as controls.

In vitro analysis of produced $\mathrm{H}_{2} \mathrm{~S}$ and reactive sulfane sulfur

A modified methylene blue method [28] was used to detect the produced $\mathrm{H}_{2} \mathrm{~S}$. Briefly, $1 \%$

zinc acetate solution $(900 \mu \mathrm{L})$ was added into the reaction solution $(100 \mu \mathrm{L})$ to convert $\mathrm{H}_{2} \mathrm{~S}$ to

$\mathrm{ZnS}$. The mixture was centrifuged at $8,000 \mathrm{~g}$ for $5 \mathrm{~min}$, and washed with deionized and

distilled water. The washing step was repeated three times. After removing the final

supernatants, deionized and distilled water $(100 \mu \mathrm{L})$ was added to the precipitates $(\mathrm{ZnS})$ and adequately mixed. Then, the solution was incubated with $300 \mu \mathrm{L}$ of $1 \%$ zinc acetate, $50 \mu \mathrm{L}$ of $20 \mathrm{mM}$ DPDA (N,N-dimethyl-p-phenylenediamine) and $30 \mathrm{mM} \mathrm{FeCl}$ in $7.2 \mathrm{~N} \mathrm{HCl}$ for 30 min. The samples were centrifuged at $8,000 \mathrm{~g}$ for $5 \mathrm{~min}$ and transferred into 96 -well plates to measure the $\mathrm{OD}_{630}$. NaHS was used to make the standard curve.

Reactive sulfane sulfur was analyzed by using a previously reported method [29]. Briefly, the sample $(50 \mu \mathrm{L})$ was mixed with $25 \mathrm{mM}$ monobromobimane $(\mathrm{mBBr}, 5 \mu \mathrm{L})$ in acetonitrile and incubated in the dark at room temperature for $30 \mathrm{~min}$. An equal volume of acetic acid and acetonitrile mixture (v/v, 1:9) was added to precipitate proteins. The precipitates were removed via centrifugation at $12,000 \mathrm{~g}$ for $2 \mathrm{~min}$. The obtained supernatant was subjected to LC-ESI-MS analysis (Ultimate 3000, Burker impact HD).

Statistical Analysis 

biological samples. The data have been deposited in https://www.biosino.org/node/ with ID: are presented as mean \pm S.D.

\section{Results}

Rdl2 is the main enzyme for RSS biogenesis in S. cerevisiae mitochondria

Crs1 in haploid strain BY4742 is lethal, we performed the knock-out experiment in the 
246

247

248

249

250

251

Rd11 and 2 ORFs in S. cerevisiae BY4742 genome. The Mito Tracker Red CMSRos was used to label BY4742 mitochondria. Rd11/2-GFP and CMSRos co-location analysis showed that Rd12 particularly located in mitochondria; whereas, Rdl1 mainly located in cytoplasm (Fig. 1E). We isolated intact mitochondria from BY4742 (wt) and the RDL2 deletion ( $\Delta r d l 2)$ mutant, in which the mitochondrial RSS detection probe mit-psGFP [26] was expressed. The wt mitochondria contained more RSS than did the $\Delta r d l 2$ counterparts, as represented by a higher 408/488 fluorescence ratio (Fig. 2A). The isolated mitochondria were then treated with cysteine, thiosulfate, or organic polysulfide $\left(\mathrm{RS}_{\mathrm{n}} \mathrm{R}, \mathrm{n} \geq 2\right)$ - the three potential substrates of sulfurtransferases. The addition of cysteine caused no RSS increase, indicating that again Crs1 did not use cysteine to produce RSS. Thiosulfate and dimethyl trisulfide (MeSSSMe) caused $27 \%$ and $261 \%$ increases of RSS, respectively, in wt mitochondria (Fig. 2B). Whereas, thiosulfate caused no increase, but MeSSSMe caused 66\% increase of RSS in $\Delta r d l 2$ mitochondria (Fig. 2C). The RDL2 gene was cloned and expressed in E. coli BL21 (DE3).

The addition of thiosulfate and MeSSSMe increased RSS in RDL2-expressing E. coli, but did not in the E. coli host (Fig. 2D and 2E).

$$
\text { RSS production by Rd12 was further tested with purified Rd12. It produced RSS from }
$$

thiosulfate and MeSSSMe as detected with SSP4; the amount of RSS was positively

correlated to the amount of added Rdl2 (Fig. $2 \mathrm{~F}$ and $2 \mathrm{G}$ ). No apparent production of $\mathrm{H}_{2} \mathrm{~S}$ was detected by using a modified methylene blue method [28]. When the products of MeSSSMe reacting with Rdl2 were derivatized by monobromobimane $(\mathrm{mBBr})$ and analyzed by using LC-MS. A major peak corresponding to mB-SS-mB was detected (supplementary material, Figure S2A), indicating the production of hydrogen persulfide $\left(\mathrm{HS}_{2} \mathrm{H}, \mathrm{HS}_{2}^{-}\right.$, or $\left.\mathrm{S}_{2}{ }^{2-}\right)$. A much 
268

269

smaller peak of likely mB-SSS-mB was also observed (supplementary material, Figure S2B).

MeSSMe, but neither MeSMe nor Me-SS-mB, was detected (supplementary material, Figure S2C), indicating that Rd12 releases a sulfane sulfur atom from MeSSSMe to produce $\mathrm{HS}_{\mathrm{n}} \mathrm{H}$ and MeSSMe.

\section{Rdl2 is essential for maintaining mitochondrial health under sub-lethal levels of ROS}

Compared with wt strain, the $\Delta r d l 2$ strain showed slightly growth retardation on both a fermentable carbon source (glucose) and a none-fermentable carbon source (glycerol). When a sub-lethal level of $\mathrm{H}_{2} \mathrm{O}_{2}$ was present, the $\Delta r d l 2$ strain displayed more severe growth retardation than wt strain, especially on none-fermentable carbon source (Fig. 3A-3C), suggesting that mitochondria were impaired in the $\Delta r d l 2$ strain.

A GFP ORF was fused with the mitochondrial citrate synthase 1 (Cit1) encoding gene in genomes of both wt and $\Delta r d l 2$ strains, which were cultured in YPD medium without the addition of $\mathrm{H}_{2} \mathrm{O}_{2}$. The mitochondrial morphology was observed with a laser-scanning confocal microscope. Mitochondria in wt displayed normal morphology with mainly filamentous or granular shape; whereas, mitochondria in the $\Delta r d l 2$ strain displayed irregular shape (Fig. 3D).

The GFP fluorescence intensity was also obviously lower in $\Delta r d l 2$ than in wt. These phenomena indicated that mitochondria in the $\Delta r d l 2$ strain were abnormal.

$$
\text { Several mitochondria-related physiological characteristics were then examined. First, the }
$$
mitochondrial membrane potential of $\Delta r d l 2$ was lower than that of wt no matter with or without the addition of $\mathrm{H}_{2} \mathrm{O}_{2}$ (Fig. 3E). Second, the oxygen consumption rate of the $\Delta r d l 2$ strain was obviously lower than that of wt with or without the presence of glucose (Fig. 3F). 
Third, the relative number of mitDNA (mitochondrial DNA normalized against nuclear DNA) was lower in $\Delta r d l 2$ than in wt, especially in the presence of $\mathrm{H}_{2} \mathrm{O}_{2}$ (Fig. 3G). These results verified that the health of mitochondria was impaired by Rdl2 knock-out, and the impairment made $\Delta r d l 2$ more sensitive to ROS stress.

Systematically investigation of the physiological changes caused by knocking out Rdl2

Transcriptomics and metabolomics approaches were applied to systemically analyze the consequences of Rdl2 knock-out. Both wt and $\Delta r d l 2$ strains were treated with $2 \mathrm{mM} \mathrm{H}_{2} \mathrm{O}_{2}$ because their physiological differences were more obvious under ROS stress. In transcriptome level, 215 genes were downregulated and 156 genes were upregulated (fold change >2, $\mathrm{p}<0.05)$ in the $\Delta r d l 2$ strain compared to wt (Fig. 4A). For specification:

I) Among the 117 genes involved in glycolysis/gluconeogenesis/pentose phosphate pathway, only 11 of them were changed at transcription level (Fig. 4B), indicating the metabolism in cytoplasm was not severely affected by Rdl2 deletion. However, or 10 genes involved in tricarboxylic acid (TCA) cycle, 7 were downregulated and 3 were upregulated (Fig. 4C); for 20 genes involved in fatty acid degradation, 8 of them were downregulated (supplementary material, Figure S3); for 11 genes involved in respiration chain, 9 of them were downregulated and 2 were upregulated (Fig. 4D);

II) For 13 genes involved in anti-ROS processes, 9 of them were downregulated and 4 were upregulated (Fig. 4E); for 38 genes involved in responding to DNA damage and replication stress, 23 of them were downregulated and 15 were upregulated; for 4 genes involved in maintaining iron homeostasis, 1 of them were downregulated and 3 were 

mitochondria were impaired, and some anti-DNA damage processes were activated by Rdl2 import to mitochondria. The well-known anti-ROS genes including mitochondrial thioredoxin reductase $(T R R 1)$, thiol-specific peroxiredoxin $(A H P 1)$, and cytosolic catalase $(C T T 1)$ were all downregulated in $\Delta r d l 2$ strain, implying that their anti-ROS functions are not over-lapped with Rd12 (otherwise, they should be upregulated to compensate for the loss of Rdl2 function). mitochondrial iron-sulfur assembly enzyme (ISU1, which consumes reduced iron) implied that there was a lack of reduced iron $\left(\mathrm{Fe}^{2+}\right)$ in mitochondria of $\Delta r d l 2$ strain. with 36 showing significant abundance change between wt and $\Delta r d l 2$ strains (fold strain (Fig. 4H). The increase of reduced nicotinamide adenine dinucleotide (NADH) and lactic acid indicated that the consumption of NADH through the respiration chain was reduced.

II) The abundance of 13 metabolites was decreased in the $\Delta r d l 2$ strain compared to that of 

composing the respiration chain (Fig. 4H).

consistent with the results of transcriptomic analysis.

344 We suspected that the Rd12-generated RSS may protect mitDNA via interfering with the

$\mathrm{H}_{2} \mathrm{O}_{2}$ scavenger is present, the damage to pDNA is inhibited. $\mathrm{Fe}^{2+}(50 \mu \mathrm{M}), \mathrm{H}_{2} \mathrm{O}_{2}(50 \mu \mathrm{M})$, 
Fenton reaction.

RSS may function through reacting with $\mathrm{H}_{2} \mathrm{O}_{2}$ to decrease the production of $\mathrm{HO}^{\circ}$, or scavenging the produced $\mathrm{HO}^{\circ}$. We examined the $\mathrm{Fe}^{3+}$ production from the Fenton reaction with or without the addition of $\mathrm{S}_{8}$. The $\mathrm{Fe}^{3+}$ production from the $\mathrm{Fe}^{2+}+\mathrm{H}_{2} \mathrm{O}_{2}+\mathrm{S}_{8}$ solution was not decreased but slightly higher than that without $\mathrm{S}_{8}$ (Fig. 5D), suggesting that $\mathrm{S}_{8}$ did not react with $\mathrm{H}_{2} \mathrm{O}_{2}$ in the Fenton solution. The slight increase in $\mathrm{Fe}^{3+}$ production in the presence of $\mathrm{S}_{8}$ favorably argues that $\mathrm{S}_{8}$ reacts $\mathrm{HO}^{\circ}$ and drives the Fenton reaction forward. We also determined the rate constant of the $\mathrm{S}_{8}+\mathrm{H}_{2} \mathrm{O}_{2}$ reaction to be $1.04 \mathrm{M}^{-1} \cdot \mathrm{s}^{-1}$ (supplementary material, Figure S4), much lower than the reported rate constant of the Fenton reaction, $\sim 10^{3}$ $\mathrm{M}^{-1} \cdot \mathrm{s}^{-1}[31]$, further supporting that $\mathrm{S}_{8}$ does not react with $\mathrm{H}_{2} \mathrm{O}_{2}$ in the Fenton solution. GSH and L-ascobic acid are well-known cellular antioxidants [32,33], but neither of them showed

SC DNA protection at similar concentrations to RSS (20 $\mu \mathrm{M} \sim 300 \mu \mathrm{M}$, Fig. 5E and 5F).Thus, $\mathrm{S}_{8}$ likely scavenges $\mathrm{HO}^{\bullet}$ to protect $\mathrm{SC}$.

$\mathrm{H}_{2} \mathrm{~S}$ was recognized as an endogenous antioxidant in a profound study that led the tide of $\mathrm{H}_{2} \mathrm{~S}$ related research [34]. However, we found that it promoted pDNA cleavage in the Fenton solution (Fig. 5G), indicating it stimulates the Fenton reaction. To reveal the underlying mechanism, we mixed $\mathrm{Fe}^{3+}$ (instead of $\mathrm{Fe}^{2+}$ ), $\mathrm{H}_{2} \mathrm{O}_{2}$, and pDNA with or without $\mathrm{H}_{2} \mathrm{~S}$. The pDNA cleavage was observed in the presence of $\mathrm{H}_{2} \mathrm{~S}$, but not in its absence (Fig. 5H). Without iron, the $\mathrm{H}_{2} \mathrm{O}_{2}$ solution with $\mathrm{H}_{2} \mathrm{~S}$ showed no pDNA cleavage (Fig. 5I). These results suggested that $\mathrm{H}_{2} \mathrm{~S}$ functions through reducing $\mathrm{Fe}^{3+}$ to $\mathrm{Fe}^{2+}$ to facilitate the Fenton reaction. For verification, we analyzed the $\mathrm{Fe}^{3+}$ production from the Fenton reaction with or without $\mathrm{H}_{2} \mathrm{~S}$, and much higher $\mathrm{Fe}^{3+}$ was detected from the Fenton reaction without $\mathrm{H}_{2} \mathrm{~S}$ than with $\mathrm{H}_{2} \mathrm{~S}$ 
378

(Fig. 5D). Black precipitate (FeS) was temporary produced in the $\mathrm{Fe}^{2+}+\mathrm{H}_{2} \mathrm{O}_{2}+\mathrm{H}_{2} \mathrm{~S}$ solution, but it disappeared in $2 \mathrm{~min}$, indicating that $\mathrm{S}^{2-}$ in $\mathrm{FeS}$ is still available for reacting with $\mathrm{H}_{2} \mathrm{O}_{2}$ and $\mathrm{Fe}^{3+}$. These results suggest that $\mathrm{H}_{2} \mathrm{~S}$ enhances the Fenton reaction.

We then measured the rate constants of sulfur-containing compounds reacting with $\mathrm{HO}^{\circ}$.

$\mathrm{H}_{2} \mathrm{~S}$ slightly descended the absorbance ratio $\left(\mathrm{A}_{0} / \mathrm{A}\right)$ of the $\mathrm{HO}^{\circ}$ probe, suggesting that it actually enhanced the production of $\mathrm{HO}^{\circ}$ (from Fenton reaction) other than scavenging it (Fig.

6A). GSH modestly reacted with $\mathrm{HO}^{\circ}$, represented by a relative flat curve of the absorbance ratio; whereas GSSH and $\mathrm{S}_{8}$ rapidly reacted with $\mathrm{HO}^{\circ}$ with $13.32 \times 10^{9}$ and $8.15 \times 10^{9}$ rate constants, respectively (Fig. 6B). These results, again, indicated that RSS was efficient $\mathrm{HO}^{\circ}$ scavenger.

\section{RDL2 expresses and functions in post-logarithmic phase}

The $\Delta r d l 2$ strain released less $\mathrm{H}_{2} \mathrm{~S}$ than wt strain, detected by lead acetate papers (Fig. 7A).

We checked the transcription levels (obtained from the transcriptome data) of enzymes involved in $\mathrm{H}_{2} \mathrm{~S}$ production pathways. Cbs (encoding gene is CYS3) and Cse (encoding gene is CYS4) that are responsible for $\mathrm{H}_{2} \mathrm{~S}$ production from organic substrate (mainly cysteine) were up-regulated in $\Delta r d l 2$ strain (Fig. 7B). The enzymes responsible for $\mathrm{H}_{2} \mathrm{~S}$ production from inorganic substrates (sulfate and sulfite) were not significantly changed. These results suggested that $\Delta r d l 2$ strain actually has a higher $\mathrm{H}_{2} \mathrm{~S}$ productivity than wt strain, but most of the produced $\mathrm{H}_{2} \mathrm{~S}$ may be consumed in $\mathrm{Fe}^{3+}$ reduction, leading to a less release portion.

The intracellular ROS levels of wt and $\Delta r d l 2$ strains were compared using the DCFH-DA probe. Wt strain contained constantly lower ROS level than $\Delta r d l 2$ strain and both showed 
400

401

402

403

404

405

406

407

408

409

410

411

412

413

414

415

416

417

418

increasing ROS levels with growth time expanding (Fig. 7C). When $\mathrm{H}_{2} \mathrm{O}_{2}$ was added, ROS

level in wt strain was moderately increased; whereas, ROS level in $\Delta r d l 2$ strain was sharply

increased (Fig. 7C), indicating that RSS is critical for controlling the level of intracellular

ROS.

The Rd12-GFP expressing strain was treated with $\mathrm{H}_{2} \mathrm{O}_{2}$, and the expression of Rd12-GFP

was only slightly increased in high $\mathrm{H}_{2} \mathrm{O}_{2}$ condition (> $5 \mathrm{mM} / \mathrm{OD}_{600}$ cell) (Fig. 7D), indicating

that the expression of Rd12 might not be ROS-induced. We analyzed the expression level of

Rd12-GFP in different growth periods by flow cytometry, and observed that Rd12 mainly

expressed in post-logarithmic phases (after $12 \mathrm{~h}$ in YPD medium) (Fig. 7E). For confirmation,

we inoculated cells of 8 h-culture (in which Rdl2 had not been expressed) onto the

$\mathrm{H}_{2} \mathrm{O}_{2}$-containing agar medium, wt cells barely grew and $\Delta r d l 2$ cells totally did not grow.

When cells of $24 \mathrm{~h}$-culture were inoculated (in which Rdl2 had been expressed), wt cells grew much better while $\Delta r d l 2$ cells also showed little growth (Fig. 7F). These results indicated that the expression of Rd12 is mainly controlled by growth related system(s) and its expression is concurrent with the accumulation of intracellular ROS.

\section{Discussion}

In this study, we verified that Rd12 is the main RSS-generating enzyme in S. cerevisiae mitochondria. Rd12 deletion resulted in RSS decrease in the mitochondria. Further, we observed that Rd12 deletion leads to morphology change of mitochondria even without the treatment of $\mathrm{H}_{2} \mathrm{O}_{2}$ (Fig. 3). When facing $\mathrm{H}_{2} \mathrm{O}_{2}$ stress, Rdl2 deletion strain is more fragile with obvious changes in mitochondria. To understand the underlying mechanism, we studied the 
422 Rd12 involved reactions and found that it generates RSS via releasing sulfane sulfur atoms

423 from relatively stable sulfane sulfur carriers (Thiosulfate and $\mathrm{RS}_{\mathrm{n}} \mathrm{R}$, Fig. 2). More importantly,

424 the RSS product of $\mathrm{Rd} 22$ can scavenge $\mathrm{HO}^{\circ}$ and hence protects mitochondria from $\mathrm{HO}^{\circ}$

425 induced damages, such as loss of mitDNA, impair of mitochondria membrane, and

426 disturbance of iron homeostasis.

427 Although we detected that $\mathrm{HS}_{\mathrm{n}} \mathrm{H}$ is the main product of $\mathrm{Rd} 2$ in vitro, considering the

428 abundance of intracellular GSH, the main product should be GSSH in vivo $\left(\mathrm{GSH}+\mathrm{S}_{\mathrm{n}} \rightarrow\right.$

$\left.429 \mathrm{GSSH}+\mathrm{S}_{\mathrm{n}-1}\right)$. It is reported that $\mathrm{RSSH}$ is an excellent $\mathrm{H}$-atom $(\mathrm{H} \bullet)$ donor, which easily gives

430 its $\mathrm{H} \bullet$ to alkoxyl $\left(\mathrm{RO}^{\bullet}\right)$ with a $\sim 10^{9} \mathrm{M}^{-1} \cdot \mathrm{s}^{-1}$ rate constant [35]. RSSH then becomes $\mathrm{RSS}^{\bullet}$

431 radical, and two $\mathrm{RSS}^{\cdot}$ radicals dimerize to form one more stable $\mathrm{RSSSSR}$ with a $5 \times 10^{9} \mathrm{M}^{-1} \cdot \mathrm{s}^{-1}$

432 rate constant $[35,36]$. In contrast, the rate constant of $\mathrm{HO}^{\circ}$ reacting with DNA is at $10^{8} \mathrm{M}^{-1} \cdot \mathrm{s}^{-1}$

433 level, at least one magnitude lower than that of RSSH giving $\mathrm{H}$-atom reaction. Thus, $\mathrm{RS}_{\mathrm{n}} \mathrm{H}$

434 and $\mathrm{HS}_{\mathrm{n}} \mathrm{H}$ chemicals have the potential capability of scavenging $\mathrm{HO}^{\circ}$ before it can damage

435 DNA in vivo. For $\mathrm{S}_{\mathrm{n}}$, it is unknown how it scavenges $\mathrm{HO}^{\circ}$. Possibly via donating an electron

436 to $\mathrm{HO}^{\bullet}$ and forming $\mathrm{S}_{\mathrm{n}}{ }^{\bullet}$ itself, then two $\mathrm{S}_{\mathrm{n}} \cdot$ radicals form $\mathrm{S}_{2 \mathrm{n}}$ that has a longer chain. Further

437 studies are required to elucidate the exact mechanism. It is noteworthy that although we

438 observed that GSH and L-ascorbic acid did not protect pDNA from the Fenton reaction even

439 when their concentrations were 6-fold higher than that of Fenton solution (Fig. 5E and 5F), a

440 previous study demonstrated that GSH did show DNA protection effect at much higher

441 concentration ( $>25$ fold of Fenton solution). The authors suggested that GSH may also react

442 with $\mathrm{HO}^{\circ}$ through $\mathrm{H}$-atom transfer mechanism [37]. Nonetheless, GSH is a much less efficient

443 H-atom donor than RSS as verified previously [35,36]. 
444 Mitochondria antagonize ROS at three levels. The scavenging of $\mathrm{O}_{2}{ }^{--}$is conducted by SOD

445 and the scavenging of $\mathrm{H}_{2} \mathrm{O}_{2}$ is performed by GPX enzymes (Fig. 7). It is reported that the rate

446 constants of GPX reactions with $\mathrm{H}_{2} \mathrm{O}_{2}$ are in the range of $10^{6} \sim 10^{7} \mathrm{M}^{-1} \cdot \mathrm{s}^{-1}[38,39]$. Metal iron

447 mediated-Fenton reaction is the main origin of $\mathrm{HO}^{\circ}$ in mitochondria with a rate constant of

$448 \sim 10^{3} \mathrm{M}^{-1} \cdot \mathrm{s}^{-1}[31]$. Considering the physiological concentrations of $\mathrm{H}_{2} \mathrm{O}_{2}$ and $\mathrm{Fe}^{2+}$ are $\sim 20 \mathrm{nM}$

449 and $\sim 500 \mathrm{nM}$, respectively [8], and the rate constants of $\mathrm{RSS}+\mathrm{H}_{2} \mathrm{O}_{2}$ reactions are only 1.04

$450 \mathrm{M}^{-1} \cdot \mathrm{s}^{-1}-23.76 \mathrm{M}^{-1} \cdot \mathrm{s}^{-1}$ [40], RSS should have no chance to react with $\mathrm{H}_{2} \mathrm{O}_{2}$ in mitochondria.

451 Thus, RSS plays antioxidation function mainly through scavenging $\mathrm{HO}^{\circ}$, as we observed that

452 it reacts with $\mathrm{HO}^{\circ}$ more rapidly than GSH. This may represent the third ROS-antagonizing

453 level in mitochondria (Fig. 8).

454 On the other hand, $\mathrm{H}_{2} \mathrm{~S}$ has been deemed as an antioxidant in many reports $[34,41,42]$,

455 further studies including ours found that its reaction with $\mathrm{H}_{2} \mathrm{O}_{2}$ is slow with $2^{\text {nd }}$ rate constant

456 between $0.46 \mathrm{M}^{-1} \cdot \mathrm{s}^{-1}-0.76 \mathrm{M}^{-1} \cdot \mathrm{s}^{-1}[40]$. Considering the physiological concentration of $\mathrm{H}_{2} \mathrm{~S}$ is

457 much lower than that of RSS [15], the reaction between $\mathrm{H}_{2} \mathrm{~S}$ and $\mathrm{H}_{2} \mathrm{O}_{2}$ may not happen either

458 in vivo. Herein, we found that $\mathrm{H}_{2} \mathrm{~S}$ has promoting effect on the Fenton reaction, indicating that

$459 \quad \mathrm{H}_{2} \mathrm{~S}$ has the pro-oxidation function other than antioxidation.

460 In terms of the whole eukaryotic kingdom, there are probably four routes for mitochondria

461 to obtain reactive sulfane sulfur: exporting from cytoplasm, generating from $\mathrm{H}_{2} \mathrm{~S}$ via Sqr,

462 generating from cysteine via Mst or Crs2, and generating from sulfane sulfur stocks via

463 rhodanese (Fig. 8). These routes may function with different efficiencies and in different

464 conditions. Sqr-mediated route might be the most efficient one; however, Sqr activity is ETC

465 (electron transport chain) dependent, hence it may function mostly in hypoxic condition. 
466 Rhodanese-mediated route is oxygen independent, they may function in all conditions. For

467 cells having no Sqr (such as S. cerevisiae) or whose Sqr is not active (such as neuron), the

468 rhodanese-mediated RSS biogenesis represents a general strategy for protecting cells from

$469 \mathrm{HO}^{\circ}$-induced damage.

$470 \quad$ In conclusion, our study has three important observations:

471 i. RSS has $\mathrm{HO}^{\circ}$ scavenging function, highlighting the unparallel role of RSS among all

$472 \quad$ known natural anti ROS agents.

473 ii. $\mathrm{H}_{2} \mathrm{~S}$ stimulates the Fenton reaction, suggesting that it may promote oxidative damage,

$474 \quad$ instead of being an antioxidant.

475 iii. Rhodaneses are critical for maintaining mitochondrial health, adding a new function for

476 them in anti ROS besides sulfur metabolism.

477

478

479

480

481

482

483

484

485

486

487

\section{Acknowledgements}

The work was financially supported by grants from the National Key R\&D Program of China (2018YFA0901200) and the National Natural Science Foundation of China (91951202).

\section{Author Contributions}

H. Liu and L. Xun designed the research and made plans for the experiments; Q. Wang, Z.

Chen, and Y. Xin performed Rd12 related experiments; X. Zhang performed Crs1 related

experiments. Y. Xia helped in data interpretation. 


\section{Competing interests}

489 The authors declare no competing interests.

\section{Data availability}

492

The data that support the findings of this study are available from the corresponding author upon request

\section{References}

[1] S. Papa, Mitochondrial oxidative phosphorylation changes in the life span. Molecular aspects and physiopathological implications, Biochim. Biophys. Acta - Bioenerg. 1276 (1996). https://doi.org/10.1016/0005-2728(96)00077-1.

[2] J.B. Spinelli, M.C. Haigis, The multifaceted contributions of mitochondria to cellular metabolism, Nat. Cell Biol. 20 (2018). https://doi.org/10.1038/s41556-018-0124-1.

[3] K. Palikaras, E. Lionaki, N. Tavernarakis, Mechanisms of mitophagy in cellular homeostasis, physiology and pathology, Nat. Cell Biol. 20 (2018). https://doi.org/10.1038/s41556-018-0176-2.

[4] J.R. Friedman, J. Nunnari, Mitochondrial form and function, Nature. 505 (2014). https://doi.org/10.1038/nature12985.

[5] B. Van Houten, S.E. Hunter, J.N. Meyer, Mitochondrial DNA damage induced autophagy, cell death, and disease, Front. Biosci. - Landmark. 21 (2016). https://doi.org/10.2741/4375.

[6] J. O’Malley, R. Kumar, J. Inigo, N. Yadava, D. Chandra, Mitochondrial Stress 
510 Response and Cancer, Trends in Cancer. 6 (2020).

$511 \quad$ https://doi.org/10.1016/j.trecan.2020.04.009.

512 [7] A.Y. Andreyev, Y.E. Kushnareva, A.N. Murphy, A.A. Starkov, Mitochondrial ROS

513 metabolism: 10 Years later, Biochem. 80 (2015).

$514 \quad$ https://doi.org/10.1134/S0006297915050028.

515 [8] B. D’Autréaux, M.B. Toledano, ROS as signalling molecules: Mechanisms that

516 generate specificity in ROS homeostasis, Nat. Rev. Mol. Cell Biol. 8 (2007).

517 https://doi.org/10.1038/nrm2256.

518 [9] E.G. Hrycay, S.M. Bandiera, Involvement of Cytochrome P450 in Reactive Oxygen

519 Species Formation and Cancer, Adv. Pharmacol. 74 (2015).

520 https://doi.org/10.1016/bs.apha.2015.03.003.

521 [10] N. Lau, M.D. Pluth, Reactive sulfur species (RSS): persulfides, polysulfides, potential,

522 and problems, Curr. Opin. Chem. Biol. 49 (2019).

523 https://doi.org/10.1016/j.cbpa.2018.08.012.

524 [11] J. Shen, B.J.C. Walsh, A.L. Flores-Mireles, H. Peng, Y. Zhang, Y. Zhang, J.C.

525 Trinidad, S.J. Hultgren, D.P. Giedroc, Hydrogen Sulfide Sensing through Reactive

526 Sulfur Species (RSS) and Nitroxyl (HNO) in Enterococcus faecalis, ACS Chem. Biol.

52713 (2018). https://doi.org/10.1021/acschembio.8b00230.

528 [12] A.A. Santos, S.S. Venceslau, F. Grein, W.D. Leavitt, C. Dahl, D.T. Johnston, I.A.C.

529 Pereira, A protein trisulfide couples dissimilatory sulfate reduction to energy

530 conservation, Science (80-. ). 350 (2015). https://doi.org/10.1126/science.aad3558.

531 [13] Y. Wang, R. Yu, L. Wu, G. Yang, Hydrogen sulfide signaling in regulation of cell 
532 behaviors, Nitric Oxide - Biol. Chem. 103 (2020).

https://doi.org/10.1016/j.niox.2020.07.002.

[14] M.R. Filipovic, J. Zivanovic, B. Alvarez, R. Banerjee, Chemical Biology of $\mathrm{H}_{2} \mathrm{~S}$ Signaling through Persulfidation, Chem. Rev. 118 (2018). https://doi.org/10.1021/acs.chemrev.7b00205.

[15] T. Ida, T. Sawa, H. Ihara, Y. Tsuchiya, Y. Watanabe, Y. Kumagai, M. Suematsu, H. Motohashi, S. Fujii, T. Matsunaga, M. Yamamoto, K. Ono, N.O. Devarie-Baez, M. Xian, J.M. Fukuto, T. Akaike, Reactive cysteine persulfides and S-polythiolation regulate oxidative stress and redox signaling, Proc. Natl. Acad. Sci. U. S. A. 111 (2014). https://doi.org/10.1073/pnas.1321232111.

[16] Y. Kimura, Y. Toyofuku, S. Koike, N. Shibuya, N. Nagahara, D. Lefer, Y. Ogasawara, H. Kimura, Identification of $\mathrm{H}_{2} \mathrm{~S}_{3}$ and $\mathrm{H}_{2} \mathrm{~S}$ produced by 3-mercaptopyruvate sulfurtransferase in the brain, Sci. Rep. 5 (2015). https://doi.org/10.1038/srep14774.

[17] H. Kimura, Signalling by hydrogen sulfide and polysulfides via protein S-sulfuration, Br. J. Pharmacol. 177 (2020). https://doi.org/10.1111/bph.14579.

[18] T. Akaike, T. Ida, F.Y. Wei, M. Nishida, Y. Kumagai, M.M. Alam, H. Ihara, T. Sawa, T. Matsunaga, S. Kasamatsu, A. Nishimura, M. Morita, K. Tomizawa, A. Nishimura, S. Watanabe, K. Inaba, H. Shima, N. Tanuma, M. Jung, S. Fujii, Y. Watanabe, M. Ohmuraya, P. Nagy, M. Feelisch, J.M. Fukuto, H. Motohashi, Cysteinyl-tRNA synthetase governs cysteine polysulfidation and mitochondrial bioenergetics, Nat. Commun. 8 (2017). https://doi.org/10.1038/s41467-017-01311-y.

[19] C.M. Quinzii, L.C. Lopez, Abnormalities of hydrogen sulfide and glutathione 
554 pathways in mitochondrial dysfunction, J. Adv. Res. 27 (2021).

$555 \quad$ https://doi.org/10.1016/j.jare.2020.04.002.

556 [20] G. Rao, B. Murphy, A. Dey, S.K.D. Dwivedi, Y. Zhang, R.V. Roy, P. Chakraborty, R.

557 Bhattacharya, P. Mukherjee, Cystathionine beta synthase regulates mitochondrial

558 dynamics and function in endothelial cells, FASEB J. 34 (2020).

559 https://doi.org/10.1096/fj.202000173R.

560 [21] A. Nishimura, R. Nasuno, Y. Yoshikawa, M. Jung, T. Ida, T. Matsunaga, M. Morita,

561 H. Takagi, H. Motohashi, T. Akaike, Mitochondrial cysteinyl-tRNA synthetase is expressed via alternative transcriptional initiation regulated by energy metabolism in yeast cells, J. Biol. Chem. 294 (2019). https://doi.org/10.1074/jbc.RA119.009203.

[22] Z. Chen, X. Zhang, H. Li, H. Liu, Y. Xia, L. Xun, The complete pathway for thiosulfate utilization in Saccharomyces cerevisiae, Appl. Environ. Microbiol. 84

[23] J.L. Luebke, J. Shen, K.E. Bruce, T.E. Kehl-Fie, H. Peng, E.P. Skaar, D.P. Giedroc, The CsoR-like sulfurtransferase repressor (CstR) is a persulfide sensor in

Staphylococcus aureus, Mol. Microbiol. 94 (2014).

575

[24] J.H. Hegemann, U. Gldener, G.J. Köhler, Gene disruption in the budding yeast Saccharomyces cerevisiae., Methods Mol. Biol. 313 (2006). https://doi.org/10.1385/1-59259-958-3:129.

[25] C. Meisinger, N. Pfanner, K.N. Truscott, Isolation of yeast mitochondria., Methods Mol. Biol. 313 (2006). https://doi.org/10.1385/1-59259-958-3:033. 
576

577

578

579

580

581

582

583

584

585

586

587

588

589

590

591

592

593

594

595

596

597
[26] X. Hu, H. Li, X. Zhang, Z. Chen, R. Zhao, N. Hou, J. Liu, L. Xun, H. Liu, Developing polysulfide-sensitive gfps for real-time analysis of polysulfides in live cells and subcellular organelles, Anal. Chem. 91 (2019). https://doi.org/10.1021/acs.analchem.8b04634.

[27] A. Misak, M. Grman, Z. Bacova, I. Rezuchova, S. Hudecova, E. Ondriasova, O. Krizanova, V. Brezova, M. Chovanec, K. Ondrias, Polysulfides and products of $\mathrm{H}_{2} \mathrm{~S} / \mathrm{S}$-nitrosoglutathione in comparison to $\mathrm{H}_{2} \mathrm{~S}$, glutathione and antioxidant Trolox are potent scavengers of superoxide anion radical and produce hydroxyl radical by decomposition of $\mathrm{H}_{2} \mathrm{O}_{2}$, Nitric Oxide - Biol. Chem. 76 (2018). https://doi.org/10.1016/j.niox.2017.09.006.

[28] M. Ikeda, Y. Ishima, A. Shibata, V.T.G. Chuang, T. Sawa, H. Ihara, H. Watanabe, M. Xian, Y. Ouchi, T. Shimizu, H. Ando, M. Ukawa, T. Ishida, T. Akaike, M. Otagiri, T. Maruyama, Quantitative determination of polysulfide in albumins, plasma proteins and biological fluid samples using a novel combined assays approach, Anal. Chim. Acta. 969 (2017). https://doi.org/10.1016/j.aca.2017.03.027.

[29] Y. Xin, H. Liu, F. Cui, H. Liu, L. Xun, Recombinant Escherichia coli with sulfide:quinone oxidoreductase and persulfide dioxygenase rapidly oxidises sulfide to sulfite and thiosulfate via a new pathway, Environ. Microbiol. 18 (2016). https://doi.org/10.1111/1462-2920.13511.

[30] W. Chen, C. Liu, B. Peng, Y. Zhao, A. Pacheco, M. Xian, New fluorescent probes for sulfane sulfurs and the application in bioimaging, Chem. Sci. 4 (2013). https://doi.org/10.1039/c3sc50754h. 
598 [31] J.A. Imlay, S.M. Chin, S. Linn, Toxic DNA damage by hydrogen peroxide through the

599

600

601

602

603

604

605

606

607

608

609

610

611

612

613

614

615

616

617

618

619 fenton reaction in vivo and in vitro, Science (80-. ). 240 (1988). https://doi.org/10.1126/science.2834821.

[32] P. Nagy, C.C. Winterbourn, Redox chemistry of biological thiols, Adv. Mol. Toxicol. 4 (2010). https://doi.org/10.1016/S1872-0854(10)04006-3.

[33] R.E. Beyer, The role of ascorbate in antioxidant protection of biomembranes: Interaction with vitamin E and coenzyme Q, J. Bioenerg. Biomembr. 26 (1994). https://doi.org/10.1007/BF00762775.

[34] K. Shatalin, E. Shatalina, A. Mironov, E. Nudler, $\mathrm{H}_{2} \mathrm{~S}$ : A universal defense against antibiotics in bacteria, Science (80-. ). 334 (2011). https://doi.org/10.1126/science.1209855.

[35] J.P.R. Chauvin, M. Griesser, D.A. Pratt, Hydropersulfides: H-Atom Transfer Agents Par Excellence, J. Am. Chem. Soc. 139 (2017). https://doi.org/10.1021/jacs.7b02571.

[36] C.L. Bianco, T.A. Chavez, V. Sosa, S. Saund S., Q.N.N. Nguyen, D.J. Tantillo, A.S. Ichimura, J.P. Toscano, J.M. Fukuto, The chemical biology of the persulfide (RSSH)/perthiyl (RSS·) redox couple and possible role in biological redox signaling, Free Radic. Biol. Med. 101 (2016). https://doi.org/10.1016/j.freeradbiomed.2016.09.020.

[37] N. Spear, S.D. Aust, Effects of glutathione on Fenton reagent-dependent radical production and DNA oxidation, Arch. Biochem. Biophys. 324 (1995). https://doi.org/10.1006/abbi.1995.9921.

[38] M.P. Murphy, How mitochondria produce reactive oxygen species, Biochem. J. 417 
620

621

622

623

624

625

626

627

628

629

630

631

632

633

634

635

636

637 638

639

640

641

(2009). https://doi.org/10.1042/BJ20081386.

[39] C. Thomas, M.M. Mackey, A.A. Diaz, D.P. Cox, Hydroxyl radical is produced via the Fenton reaction in submitochondrial particles under oxidative stress: Implications for diseases associated with iron accumulation, Redox Rep. 14 (2009). https://doi.org/10.1179/135100009X392566.

[40] H. Li, H. Liu, Z. Chen, R. Zhao, Q. Wang, M. Ran, Y. Xia, X. Hu, J. Liu, M. Xian, L. Xun, Using resonance synchronous spectroscopy to characterize the reactivity and electrophilicity of biologically relevant sulfane sulfur, Redox Biol. 24 (2019). https://doi.org/10.1016/j.redox.2019.101179.

[41] B. Murphy, R. Bhattacharya, P. Mukherjee, Hydrogen sulfide signaling in mitochondria and disease, FASEB J. 33 (2019).

https://doi.org/10.1096/fj.201901304R.

[42] K.R. Olson, Hydrogen sulfide, reactive sulfur species and coping with reactive oxygen species, Free Radic. Biol. Med. 140 (2019).

https://doi.org/10.1016/j.freeradbiomed.2019.01.020.

5




\section{Figure legends}

643

644

645

646

647

648

649

650

Fig. 1. Activity and localization analyses of the enzymes pertaining to mitochondrial RSS

generation in S. cerevisiae BY4742. A) SSP4 analysis of RSS generated by Crs1 in vitro.

B\&C) SSP4 analysis of intracellular RSS of BY4742 containing the opo plasmid (as control) and the Crs1 expression plasmid. D) SSP4 analysis of intracellular RSS of the CEN CEN.PK2 wt $\left(\operatorname{crs} 1^{+/+}\right)$and $C R S 1$ knock-out $\left(\operatorname{crs} 1^{-/+}\right)$strains. E) Localization analysis of Rdl1 and 2.

CMSRos is the Mito Tracker Red dye. Data were from three independent repeats and represented as average \pm s.d.

\section{Fig. 2. In vitro and in vivo analysis of the Rdl2 contribution to mitochondrial RSS. A)}

BY4742 wt and $\Delta r d l 2$ strains harboring mit-psGFP were cultured in YPD medium until

OD600 reached 0.6 , and then 408/488 excitation ratio of the cells was examined. B)

Mitochondria harboring mit-psGFP were isolated from BY4742 wt strain, and were treated with $400 \mu \mathrm{M}$ different chemicals at $30^{\circ} \mathrm{C}$ for $1 \mathrm{~h}$, and then $408 / 488$ excitation ratio was examined. The higher the ratio, the higher the RSS. C) Mitochondria harboring mit-psGFP were isolated from BY4742 $\Delta r d l 2$ strain, and were treated with $400 \mu \mathrm{M}$ different chemicals at $30^{\circ} \mathrm{C}$ for $1 \mathrm{~h}$, and then 408/488 excitation ratio was examined. D\&E) E. coli wt and $r d l 2$ expressing strains were treated with thiosulfate and MeSSSMe. SSP4 was used to to examine the intracellular reactive sulfane sulfur. F\&G) Purified Rdl2 was mixed with its substrates and the products were analyzed using SSP4. Data were from three independent repeats. * represents difference $(\mathrm{p}<0.05)$ and $* *$ represents significant difference $(\mathrm{p}<0.01)$ in two-sided t-test. Data were from three independent repeats and represented as average \pm s.d 
Fig. 3. Examination of the role of $\mathrm{Rdl} 2$ in maintaining mitochondrial health under $\mathrm{ROS}$

stress. A) BY4742 wt and $\Delta r d l 2$ strains were cultivated in SD or YPG agar plates. $2 \mathrm{mM}$

$\mathrm{H}_{2} \mathrm{O}_{2}$ was added. B\&C) BY4742 wt and $\Delta r d l 2$ strains were cultivated in SD or YPG liquid

medium. $2 \mathrm{mM} \mathrm{H}_{2} \mathrm{O}_{2}$ was added. D) Mitochondrial morphology analysis of BY4742 wt and

$\Delta r d l 2$ strains. The strains containing Cit1-GFP were cultivated in YPD medium to log phase

without $\mathrm{H}_{2} \mathrm{O}_{2}$ treatment. Images were captured with the laser confocal microscope LMS900.

E) Mitochondrial membrane potential analysis of wt and $\Delta r d l 2$ strains. F) Oxygen

consumption analysis of wt and $\Delta r d l 2$ strains. G) mit-DNA analysis of wt and $\Delta r d l 2$ strains.

Embedded figure: the strains were treated with $2 \mathrm{mM} \mathrm{H}_{2} \mathrm{O}_{2}$. Data were calculated from three

independent repeats.

Fig. 4. Transcriptomics and targeted metabolomics analysis of BY4742 wt and $\mathbf{A r d l 2}$ analysis data were calculated from three independent repeats. 
686

687

688

689

690

691

692

693

694

695

696

697

698

699

700

701

702

703

704

705

706

707

reagents and thiosulfate $(300 \mu \mathrm{M}) ; 4$, pDNA treated with Fenton reagents and products from

Rd12 + thiosulfate reaction (10 fold-dilution); 5, pDNA treated with Fenton reagents and

products from $\mathrm{Rd} 2$ + thiosulfate reaction (2.5 fold dilution); 6, pDNA treated with Fenton

reagents and MeSSSMe $(300 \mu \mathrm{M}) ; 7$, pDNA treated with Fenton reagents and products from

Rd12 + MeSSSMe reaction (10 fold-dilution); 8, pDNA treated with Fenton reagents and

products from Rd12 + MeSSSMe reaction (2.5 fold-dilution). B,C,E,F,\&G) 1, untreated

pDNA; 2, pDNA treated with Fenton reagents; 3-n, pDNA treated with Fenton reagents and

tested chemicals $(20 \mu \mathrm{M}-300 \mu \mathrm{M})$. D) $\mathrm{Fe}^{3+}$ production from the Fenton reaction. $\mathrm{CK}$ is the

mixture of $500 \mu \mathrm{M} \mathrm{Fe}^{2+}+500 \mu \mathrm{M} \mathrm{H}_{2} \mathrm{O}_{2} ; 500 \mu \mathrm{M} \mathrm{S}_{8}$ or $\mathrm{H}_{2} \mathrm{~S}$ was added. $\left.\mathrm{H}\right) 1$, untreated

pDNA; 2, pDNA treated with $50 \mu \mathrm{M} \mathrm{Fe}^{3+}+50 \mu \mathrm{M} \mathrm{H}_{2} \mathrm{O}_{2} ; 3-7$, pDNA treated with $50 \mu \mathrm{M} \mathrm{Fe}{ }^{3+}$,

$50 \mu \mathrm{M} \mathrm{H}_{2} \mathrm{O}_{2}$, and $\mathrm{H}_{2} \mathrm{~S}(20 \mu \mathrm{M}-300 \mu \mathrm{M})$. I) 1, untreated pDNA; 2, pDNA treated with $50 \mu \mathrm{M}$

$\mathrm{H}_{2} \mathrm{O}_{2} ; 3-7$, pDNA treated with $50 \mu \mathrm{M} \mathrm{H}_{2} \mathrm{O}_{2}$ and $\mathrm{H}_{2} \mathrm{~S}(20 \mu \mathrm{M}-300 \mu \mathrm{M})$. The SC percentage

data were calculated from three independent repeats.

Fig. 6. Kinetic analysis of $\mathrm{HO}^{\circ}$ radical scavenging activity of certain compounds using

the modified CUPRAC method. A) Kinetic plots measured using the HO${ }^{\circ}$ probe

3,5-dimethoxybenzoate. B) Rate constants calculated from the kinetic plots. Details of the

CUPRAC method was described in supporting material.

Fig. 7. In vitro analysis of the interaction between Rd12 and ROS. A) $\mathrm{H}_{2} \mathrm{~S}$ release

detection using lead acetate papers. The strains were cultivated in SD medium for $80 \mathrm{~h}$. B) 
708 Transcription levels of enzymes involved in $\mathrm{H}_{2} \mathrm{~S}$ production pathways. Data were from

709 transcriptomic analysis. The bar represent the average readcount of 6 parallel biological

710 samples. C) Analysis of the intracellular ROS of BY4742 wt and $\Delta r d l 2$ strains. D) The

711 expression of Rd12-GFP was only slightly increased in high $\mathrm{H}_{2} \mathrm{O}_{2}$ condition (5 mM). E) The

712 expression of Rd12-GFP was different at different growth phases. F) BY4742 wt cells of

713 stationary phase were more resistant to $\mathrm{H}_{2} \mathrm{O}_{2}$ than mid-log phase cells. Data were from three

714 independent repeats and represented as average \pm s.d

715

716 Fig. 8. Schematic representation of the mitochondrial RSS biogenesis routes and

717 functions. S. cerevisiae mitochondria contain no Sqr or Mst. Rd12 is the only enzyme that

718 generates RSS, which can scavenge HO

719

720 


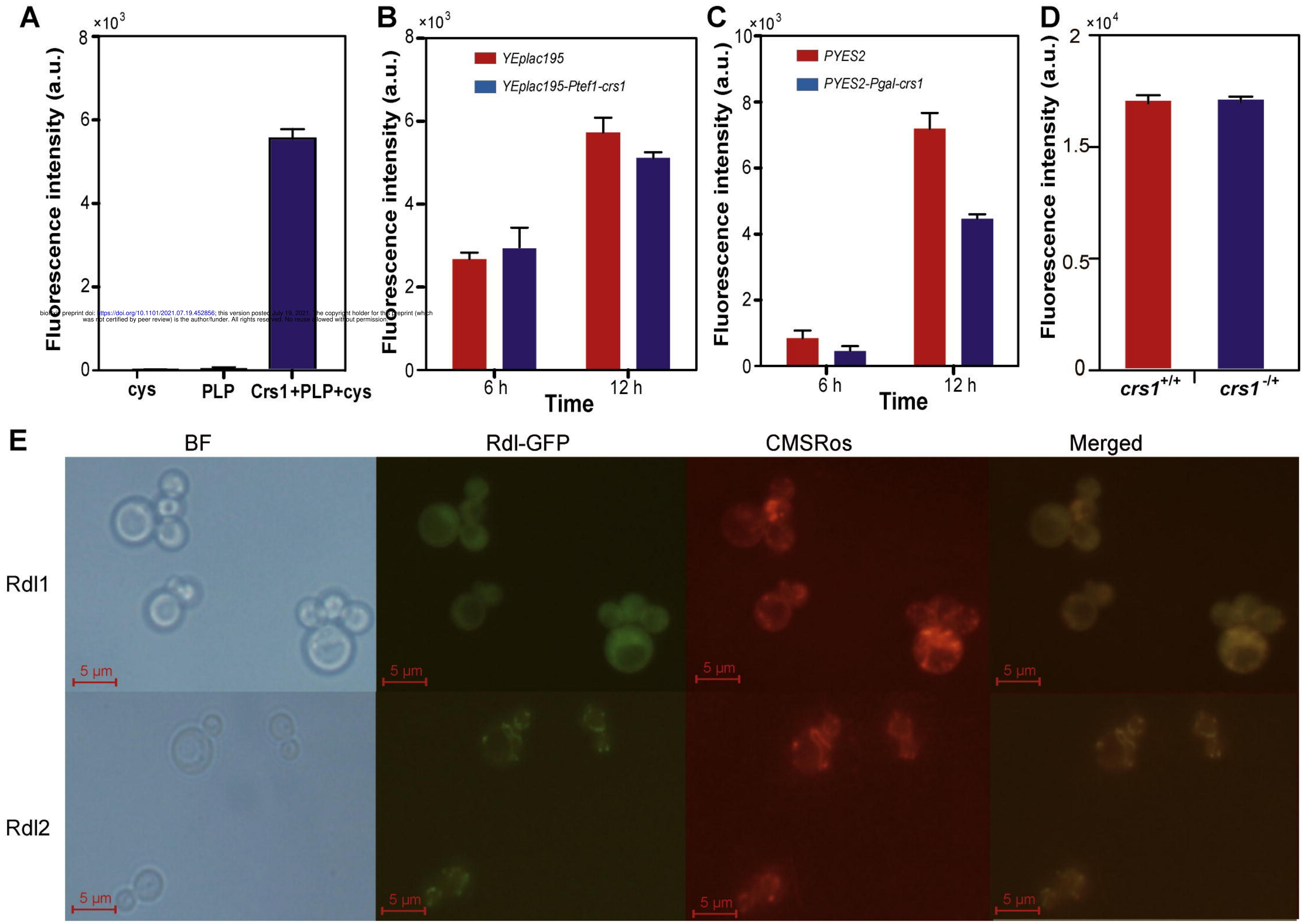




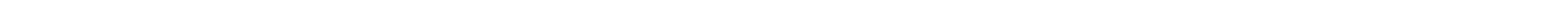




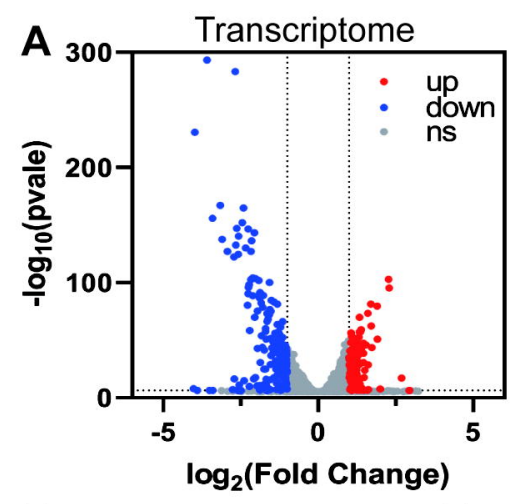

B

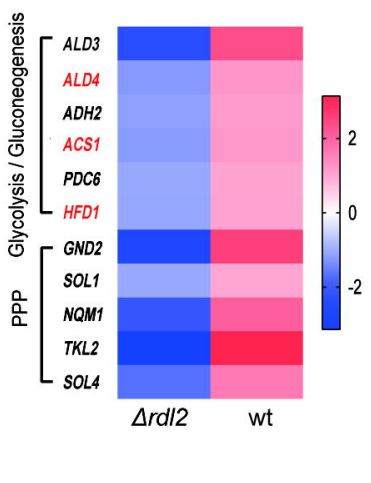

C
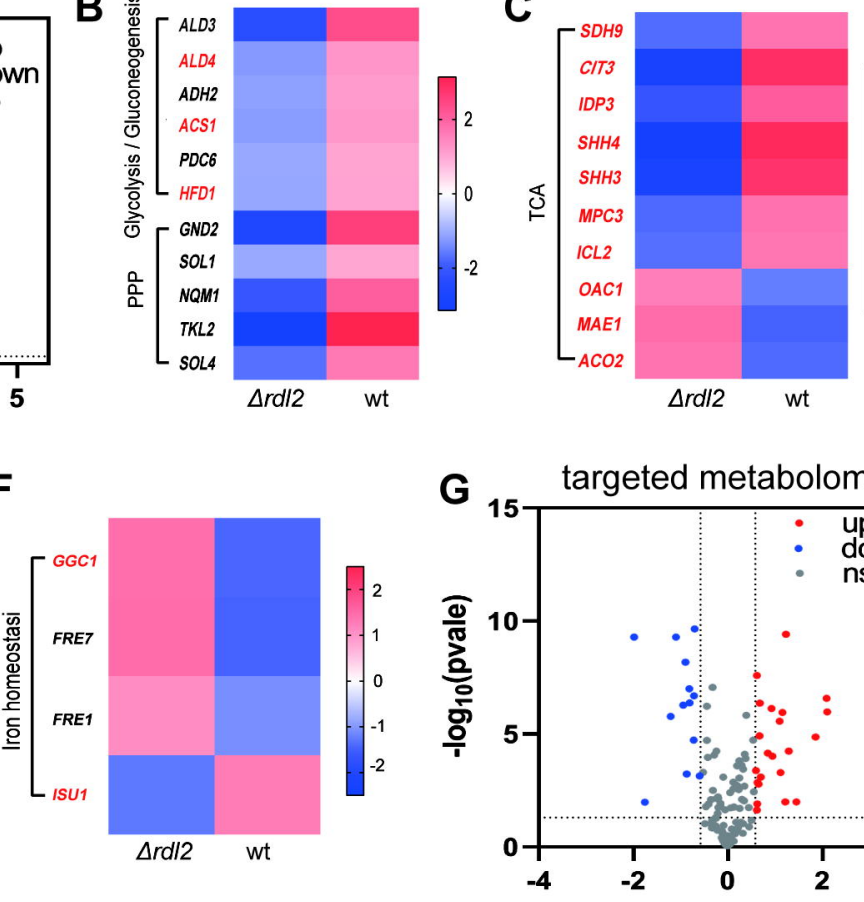

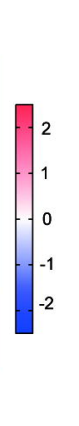

2
G

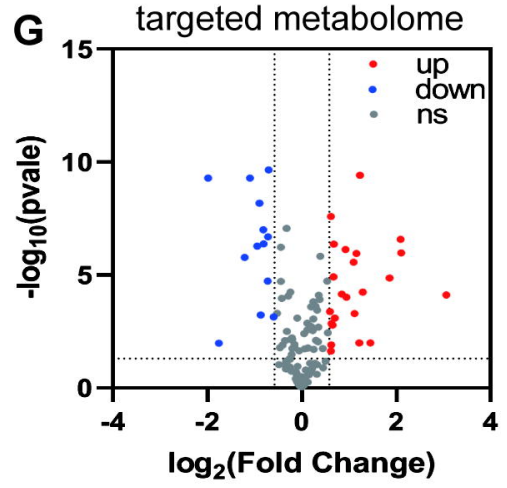

D
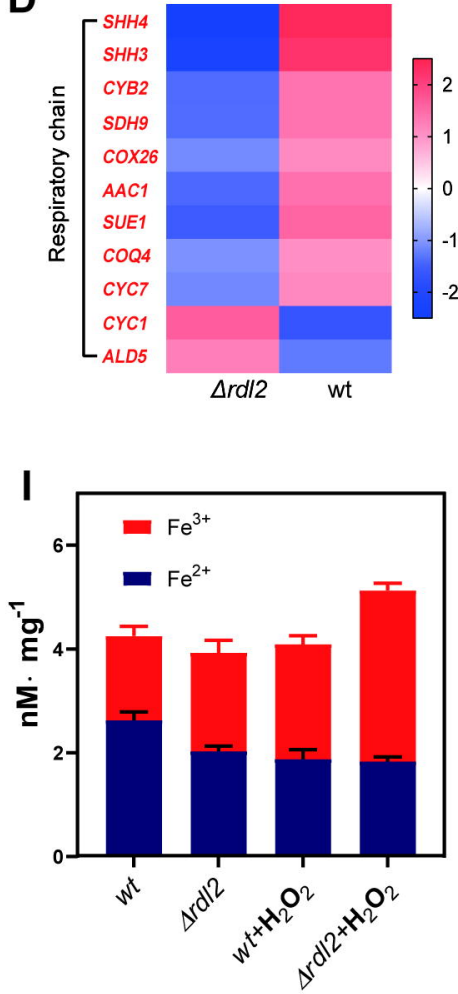

H

wt

$\Delta r d / 2$

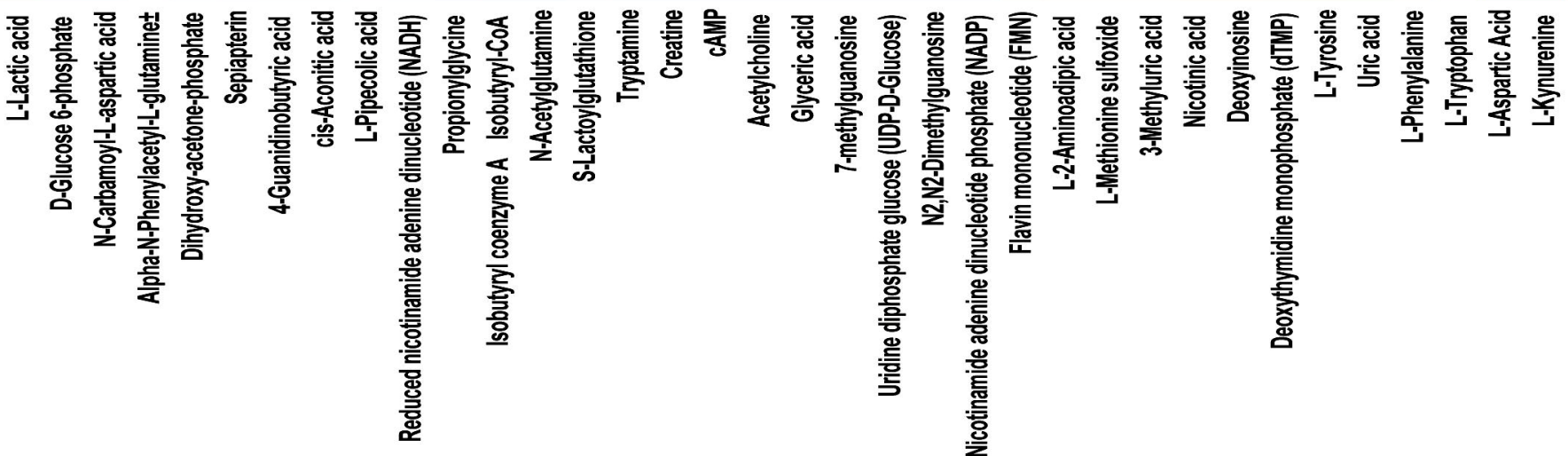




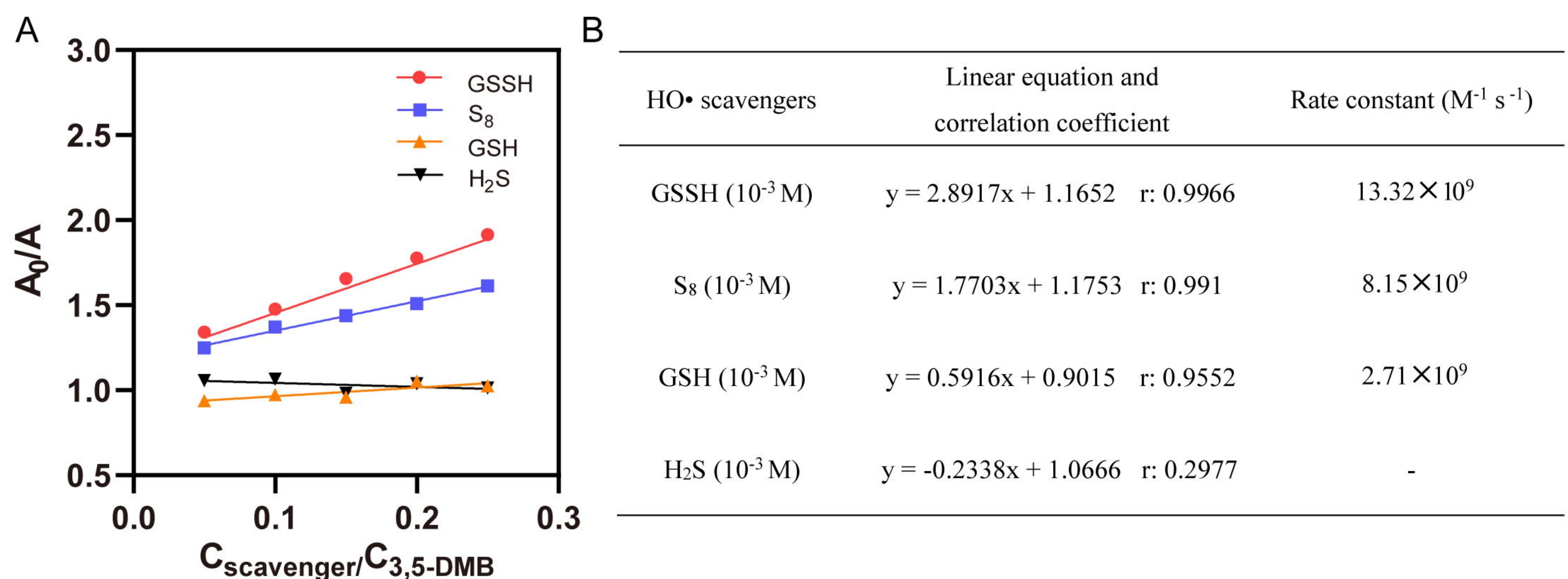




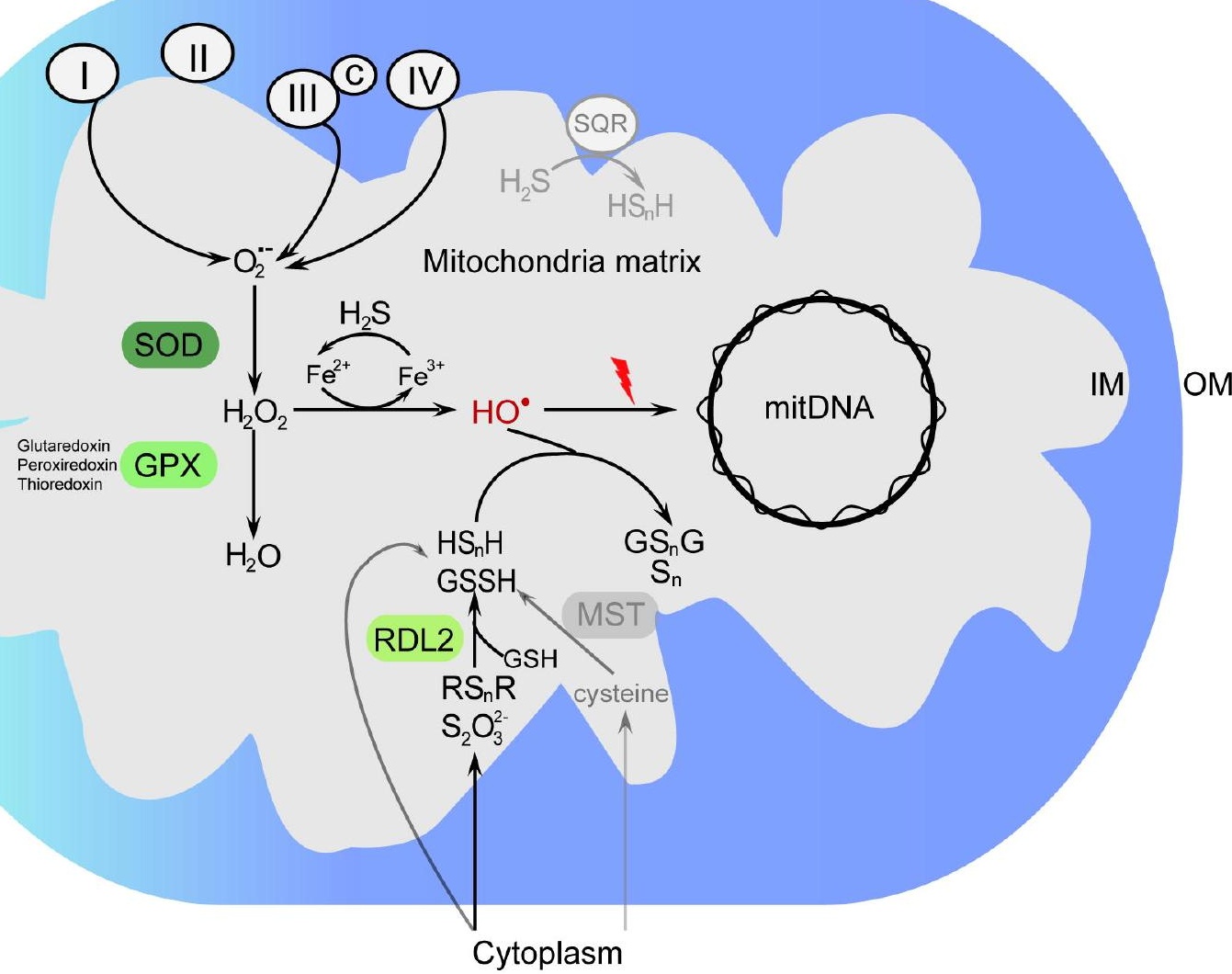

